\title{
Disease and Diagnosis
}

\section{Determining the Relationship Between Fever of Without focus and Latent Pneumonia in Feverish Children in Bandar Abbas, Iran}

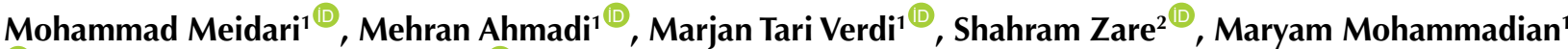 \\ (1) Mohammad Bagher Rahmati ${ }^{1 *(1)}$
}

'Department of Pediatrics, Faculty of Medicine, Pediatric Research Center, Hormozgan University of Medical Sciences, Bandar Abbas, Iran.

${ }^{2}$ Department of Social Medicine, Medical School, Hormozgan University of Medical Sciences, Bandar Abbas, Iran.

\begin{abstract}
Background: Fever is one of the most common causes of children's referral to the emergency department, for which in $20 \%$ of cases no clear source is found. Latent pneumonia is not easily differentiable as one of the differential diagnoses of fever of unknown origin (FUO). This study aimed to determine the relationship between FUO and latent pneumonia in feverish children referring to pediatric emergency department.

Materials and Methods: The present analytical research was carried out on 220 children with FUO aged 3-36 months referred to pediatric hospital of Bandar Abbas, Iran in 2019. To find the signs and symptoms, demographic information, history, and physical examination results were recorded by a physician using a predetermined checklist. Chest $\mathrm{x}$-ray and blood sample were prepared for white blood cell (WBC) count, C-reactive protein (CRP), and absolute neutrophil count (ANC).

Results: The mean age of the patients was $18.38 \pm 8.6$ months. There was no significant difference between the mean fever, pulse rate, respiratory rate, WBC count, erythrocyte sedimentation rate (ESR), and ANC among the three groups differentiated by their diagnosis. The mean CRP in the bacterial pneumonia group was $68.17 \pm 24.13$, while it was $35.00 \pm 20.43$ in the viral infection group and $35.71 \pm 26.20$ in the group of other diseases; the difference was statistically significant $(P=0.004)$.

Conclusion: Although there was no significant difference between WBC, ANC, and ESR and latent pneumonia, there was a significant difference between CRP and latent pneumonia, whose value was larger in these patients.

Keywords: Fever without focus, Latent pneumonia, Children
\end{abstract}

\author{
*Correspondence to \\ Mohammad Bagher \\ Rahmati, Department \\ of Pediatrics, Faculty \\ of Medicine, Pediatric \\ Research Center, \\ Hormozgan University of \\ Medical Sciences, Bandar \\ Abbas, Iran. \\ Tel: +989177615397; \\ Email: mbrahmati@yahoo. \\ com
}

Received: October 27, 2020, Accepted: December 28, 2020, ePublished: June 28, 2021

\section{Introduction}

Fever is one of the most common causes of children's referral to emergency; however, in $20 \%$ of cases no specific source is found for it after taking the history and complete examination, which is called fever of unknown origin (FUO) (1). Among the children suffering from FUO, some may have latent bacterial infections including bacteremia, urinary tract infection, latent pneumonia, or rarely premature bacterial meningitis (2). Latent pneumonia, as one of the differential diagnoses of FUO, is not easily differentiable, and its predictive factors are very limited (3). Infants with FUO undergo various therapeutic and diagnostic strategies including Boston, Rochester, and Philadelphia criteria based on their age (4). Chest x-ray is not used routinely in primary assessment of children with FUO to diagnose pneumonia
(5). Studies suggest no need to use $\mathrm{x}$-ray for children younger than three months of age. However, regarding children above three months without accompanying symptoms such as coughs, tachypnea, crackles, and leukocytosis, the limited data have contributed to unclear indication on the importance of performing chest x-ray at these ages (6). The results of the study by Bachur et al recommended chest $\mathrm{x}$-ray in children with a very high fever $\left(39^{\circ} \mathrm{C}\right.$ and higher rectally) or leukocytosis (more than $\left.20 \times 10^{9} / \mathrm{L}\right)(7)$. Many physicians use white blood cell (WBC) count to investigate FUO in children with suspicion of bacterial infection (8), particularly in those who are younger, have a high-grade fever, and prolonged fever. Elevated WBC count may justify initiating empirical antibiotic treatment due to worries about serious bacterial infections (SBIs) and requesting further 
paraclinical studies (4). Accordingly, this study aimed to determine the relationship between FUO and latent pneumonia in feverish children referred to pediatric emergency department for timely differentiation from other diagnoses.

\section{Materials and Methods}

In this descriptive and analytical study, 220 children aged 3-36 months referred to pediatric hospital of Bandar Abbas, Iran in 2019 were investigated. The inclusion criteria were age between 3 and 36 months, high-grade fever (temperature above $38^{\circ} \mathrm{C}$ ), absence of clinical findings favoring a specific origin for the fever, the patient's parental consent to participate in the study, and absence of underlying disease that could engender fever. FUO was defined as above $38^{\circ}$ rectally lasting less than seven days for which no source of infection could be identified in the body. In this study, the subjects were chosen through available sampling method. After describing the study objectives and acquiring written informed consent from the children's parents, demographic information, history, and physical examination (vital signs) of children for finding the signs and symptoms were recorded by physician in a predetermined checklist. Chest x-ray and blood sample were prepared, with the latter performed to investigate WBC count, absolute neutrophil count (ANC), erythrocyte sedimentation rate (ESR), and C-reactive protein (CRP). This study was performed in a section and region for which pneumococcus vaccine is not used, and only hemophilus influenzae type B vaccine is injected. The data were analyzed by SPSS software version 23.0 (IBM SPSS Statistics for Windows, Armonk, NY: IBM Corp), based on descriptive statistics, chi-square test, and one-way analysis of variance. In this study, $P$ value $<0.05$ was considered statistically significant.

\section{Results}

This study examined 220 children aged 3-36 months with Unknown origin fever FUO. The mean age of the patients was $18.38 \pm 8.6$ months. The frequency of the male gender was $53.2 \%$ (117 patients) and that of female gender was $46.8 \%$ (103 patients). Out of the 220 patients with FUO, nine were diagnosed as viral infection and six as pneumonia, while 205 fell in the other disease groups. In the radiographies taken, five, four, and six cases showed hyperinflation, paracardiac involvement, and lobar involvement, respectively; meanwhile, 206 had no pulmonary involvement (Table 1).

The mean WBC count, ANC, CRP, ESR, heart rate, respiratory rate, and fever was $11.94 \pm 4.88,6652 \pm 3692$, $35.94 \pm 25.99,48.63 \pm 32.31,115.56 \pm 16.13,36.09 \pm 10.15$, and $38.88 \pm 1.10$, respectively. Each of these indicators has been provided in Table 2 in terms of type of pneumonia, viral infection, and other diseases. Regarding WBC, ANC, ESR, heart rate, respiratory rate, and fever, there was no significant difference between the groups. On the other hand, there was a statistically significant difference between different groups regarding CRP $(P=0.004)$. To understand which two groups had significant differences, post hoc test was conducted (Table 3 ). The results indicated that there was a significant difference between bacterial pneumonia and other disease groups $(P=0.004)$.

Table 1. Frequency of Gender, Diagnosis, and Types of Lung Radiographic Findings of the Participants

\begin{tabular}{|c|c|c|c|c|}
\hline Variables & Subgroups & & Number & Percent \\
\hline \multirow{2}{*}{ Gender } & Male & & 117 & 53.2 \\
\hline & Female & & 103 & 46.8 \\
\hline \multirow{4}{*}{ Diagnosis } & Bacterial pneumonia & Lobar & 6 & 3 \\
\hline & \multirow{2}{*}{ Viral infection } & Hyperinflation & 5 & 2 \\
\hline & & Paracardiac & 4 & 2 \\
\hline & Others & Normal & 205 & 93 \\
\hline
\end{tabular}

Table 2. The Results of Statistical Test, Mean, and Standard Deviation of Vital Signs and Laboratory Data of Participants

\begin{tabular}{|c|c|c|c|c|}
\hline Variables & Groups & Mean & SD & $P$ value \\
\hline & Bacterial pneumonia & 115.39 & 15.90 & \\
\hline \multirow[t]{3}{*}{ Heart rate } & Viral infection & 121.22 & 21.59 & 0.534 \\
\hline & Others & 113.17 & 16.58 & \\
\hline & Bacterial pneumonia & 41.17 & 13.19 & \\
\hline \multirow{3}{*}{$\begin{array}{l}\text { Respiratory } \\
\text { rate }\end{array}$} & Viral infection & 39.56 & 12.14 & 0.253 \\
\hline & Others & 35.79 & 9.92 & \\
\hline & Bacterial pneumonia & 39.06 & 1.61 & \\
\hline \multirow[t]{3}{*}{ Fever } & Viral infection & 38.85 & 0.78 & 0.917 \\
\hline & Others & 38.87 & 1.10 & \\
\hline & Bacterial pneumonia & $13.79 \times 10^{3}$ & $3.98 \times 10^{3}$ & \\
\hline \multirow[t]{3}{*}{ WBC } & Viral infection & $10.82 \times 10^{3}$ & $4.47 \times 10^{3}$ & 0.511 \\
\hline & Others & $11.97 \times 10^{3}$ & $4.92 \times 10^{3}$ & \\
\hline & Bacterial pneumonia & 6519.33 & 2487.34 & \\
\hline \multirow[t]{3}{*}{ ANC } & Viral infection & 5499.16 & 3556.46 & 0.630 \\
\hline & Others & 6706.54 & 3731.86 & \\
\hline & Bacterial pneumonia & 68.17 & 24.13 & \\
\hline \multirow[t]{3}{*}{ CRP } & Viral infection & 35.00 & 20.43 & 0.004 \\
\hline & Others & 35.71 & 26.20 & \\
\hline & Bacterial pneumonia & 62.50 & 34.68 & \\
\hline \multirow[t]{2}{*}{ ESR } & Viral infection & 56.78 & 33.58 & 0.126 \\
\hline & Others & 47.87 & 35.13 & \\
\hline
\end{tabular}

Abbreviations: ANC, Absolute neutrophilic count; WBC, white blood cell; CRP, C-reactive protein; ESR, erythrocyte sedimentation rate.

Table 3. The Results of Scheffe Post Hoc Analysis

\begin{tabular}{llccc}
\hline Variables & Groups & Mean Diff & SD & P Value \\
\hline \multirow{2}{*}{ CRP } & Bacterial pneumonia & Others & -6.20 & 0.005 \\
& & Viral infection & 16.00 & 0.07 \\
\cline { 2 - 5 } & Viral infection & Others & 9.80 & 0.997 \\
\hline Abbreviation: CRP, C-reactive protein. & & &
\end{tabular}




\section{Discussion}

No clear source is found for the fever of $20 \%$ of feverish children referred to the emergency departments after acquiring the history and complete examination, which is known as FUO. Failure to find the source of fever complicates the diagnosis and treatment of patients. Accordingly, it is still important to find paraclinical and imaging findings to diagnose the source. For example, in order to find latent pneumonia as one of the differential diagnosis of FUO, using chest $\mathrm{x}$-ray, WBC count, CRP, ESR, and absolute number of neutrophils is notable.

In the present study, out of 220 participants, six had pneumonia with lobar involvement radiographic profile, and nine suffered from lower risk retract viral infection with paracardiac (5 cases) and hyperinflation (4 cases) involvement radiographic profile. In this regard, Murphy et al conducted a study to identify the predictive factors of latent pneumonia in feverish children who had received conjugated pneumococcal vaccine on 2,128 children. In their study, 1084 had absolutely no clinical symptom of pneumonia, out of whom $5.3 \%$ had latent pneumonia. This number is almost in line with the results of the present study (6). In the study by Shah et al to determine the predictive factors and incidence of latent pneumonia in patients who had undergone chest x-ray examination; out of 308 studied patients, 21 (6.8\%) had latent pneumonia, which is almost in accordance with the results of present study (9). In the study by Bachur et al, 225 patients received chest $\mathrm{x}$-ray examination. Based on this radiography, $32(40 \%)$ patients who had respiratory findings suffered from pneumonia, while 38 (26\%) who had no clinical findings in favor of pneumonia and only suffered from leukocytosis had pneumonia. In other words, this latter group had latent pneumonia. The reason of the higher number of latent pneumonia cases in this study can be due to the inclusion criteria, which studied patients with a higher risk (leukocytosis above 20000 and temperature of 39 and above) (7).

In the present study, the mean pulse rate in the bacterial pneumonia, viral infection, and other disease groups was as follows: $115.39 \pm 15.90,121.22 \pm 21.59$, and $113.17 \pm 16.58$, which had no significant difference $(P=0.534)$. The mean respiratory rate in the bacterial pneumonia, viral infection, and other disease groups was as follows: $41 / 17 \pm 13.19,39.56 \pm 12.14$, and $35.79 \pm 9.92$, which again showed no significant difference $(P=0.534)$. The mean temperature in the bacterial pneumonia, viral infection, and other disease groups was $39.06 \pm 1.61$, $38.85 \pm 12.14$, and $38.87 \pm 1.10$, indicating no significant difference $(P=0.534)$. In the study by Rutman et al, the mean respiratory rate in the pneumonia and nonpneumonia groups was 37 and 36 respectively, and the mean temperature in these two groups was 39.8 and 38.4 respectively, showing no significant difference (10). In the study by Murphy et al, the mean respiratory rate in the pneumonia and non-pneumonia groups was 31.6 and 30.5, and the mean temperature was 39.5 and 39.4 , showing no significant difference (6). The results of these studies are in accordance with those of the present research. Hence, it can be concluded that pulse rate, respiratory rate, and fever have no association with latent pneumonia, and they cannot be used to differentiate between latent pneumonia and other diagnoses.

In the present study, the mean WBC count in the bacterial pneumonia, viral infection, and other disease groups was reported $13.79 \times 10^{3} \pm 3.98 \times 10^{3}, 10.82 \times 10^{3} \pm$ $4.47 \times 10^{3}$, and $11.97 \times 10^{3} \pm 4.92 \times 10^{3}$, respectively, showing no significant difference $(P=0.511)$. In the study by Shah et al, the mean WBC count in the latent pneumonia and non-pneumonia groups was reported $15.40 \times 10^{3}$ and $17.60 \times 10^{3}$, indicating no significant difference $(P=0.74)$ (9). In the research by Rutman et al, the mean WBC count in the pneumonia and non-pneumonia groups was $26.30 \times 10^{3}$ and $24.10 \times 10^{3}$, respectively (10), showing no significant difference, and being in line with the results of present study. In the study by Murphy et al, the mean WBC count in the latent pneumonia and nonpneumonia groups was $21.50 \times 10^{3}$ and $14.60 \times 10^{3}$, which was significant $(P<0.01)(6)$. The reason of this difference with the present study can be attributed to the study subjects because the mentioned research investigated those receiving conjugated pneumococcal vaccine and had a larger sample size.

In the present study, the mean CRP in bacterial pneumonia, viral infection, and other disease groups was $68.17 \pm 24.13,35.00 \pm 20.43$, and $35.71 \pm 26.20$ respectively, which showed a significant difference with each other $(P=0.004)$. In the study by Mintegi et al, the probability of developing latent pneumonia with a CRP above 100 was 3.42 as large compared to those with CRP below 100 (5). In the study by Andreola et al, CRP and prolactin had a special role in diagnosing SBIs. In this study, CRP was significantly higher in the group suffering SBI compared to the non-SBI group $(P<0.001)(11)$. In the study by Esposito et al, CRP was significantly higher in the group with SBI compared to non-SBI group $(P<0.001)(12)$. Based on the present study which specifically dealt with the relationship between CRP and latent pneumonia and according to recent studies, it could be concluded that we cannot solely rely on WBC to prove and diagnose the source of infection, especially in patients with FUO, and factors such as CRP should also be included in judgment. Accordingly, CRP is helpful in SBI diagnosis in addition to using just $\mathrm{WBC}$ and $\mathrm{ANC}$.

\section{Conflict of Interest Disclosure}

The authors declare no conflict of interests.

\section{Acknowledgements}

The authors are thankful to our counsellors in Clinical Research Development Center of Children Hospital, Hormozgan University of Medical Sciences, Bandar Abbas, Iran. We also 
thank the staff of pediatric emergency ward, as well as the patients and their families who participated in this study.

\section{Ethical Statement}

Our study was conducted according to the 1964 Declaration of Helsinki and its later amendments or comparable ethical standards. The present study was conducted after obtaining informed consent from all participants, all records were anonymized and deidentified prior to the analysis. This study was approved by the ethics committee of Hormozgan University of Medical Sciences (IR.HUMS.REC.1398.236).

\section{Authors' Contributions}

MBR contributed to the study design, concept, and editing the manuscript. MM wrote the manuscript and performed the data collection. MA contributed to the study design, concept, and editing the manuscript. MTV contributed to the study design, concept, and editing the manuscript. SZ done statistical analysis.

\section{Funding/Support}

The study was funded by Hormozgan University of Medical Sciences.

\section{Informed Consent}

The present study was conducted after obtaining informed consent from all participants.

\section{References}

1. Kliegman R, Stanton B, St Geme JW 3rd, Schor NF, Behrman RE, Nelson WE. Nelson Textbook of Pediatrics. Philadelphia, PA: Elsevier Inc; 2020.

2. Mahajan P, Stanley R. Fever in the toddler-aged child: old concerns replaced with new ones. Clin Pediatr Emerg Med. 2008;9(4):221-7. doi: 10.1016/j.cpem.2008.09.003.

3. Yilmaz HL, Özkaya AK, Sarı Gökay S, Tolu Kendir Ö, Şenol H. Point-of-care lung ultrasound in children with community acquired pneumonia. Am J Emerg Med. 2017;35(7):964-9. doi: 10.1016/j.ajem.2017.01.065.

4. Baraff LJ. Management of fever without source in infants and children. Ann Emerg Med. 2000;36(6):602-14. doi: 10.1067/mem.2000.110820.

5. Mintegi S, Benito J, Pijoan JI, Marañon R, Peñalba A, Gonzalez A, et al. Occult pneumonia in infants with high fever without source: a prospective multicenter study. Pediatr Emerg Care. 2010;26(7):470-4. doi: 10.1097/ PEC.0b013e3181e582e4.

6. Murphy CG, van de Pol AC, Harper MB, Bachur RG. Clinical predictors of occult pneumonia in the febrile child. Acad Emerg Med . 2007;14(3):243-9. doi: 10.1197/j. aem.2006.08.022.

7. Bachur R, Perry H, Harper MB. Occult pneumonias: empiric chest radiographs in febrile children with leukocytosis. Ann Emerg Med. 1999;33(2):166-73. doi: 10.1016/s0196-0644(99)70390-2.

8. Gómez B, Mintegi S, Benito J, Egireun A, Garcia D, Astobiza E. Blood culture and bacteremia predictors in infants less than three months of age with fever without source. Pediatr Infect Dis J. 2010;29(1):43-7. doi: 10.1097/ INF.0b013e3181c6dd14.

9. Shah S, Mathews B, Neuman MI, Bachur R. Detection of occult pneumonia in a pediatric emergency department. Pediatr Emerg Care. 2010;26(9):615-21. doi: 10.1097/ PEC.0b013e3181ef04a3.

10. Rutman MS, Bachur R, Harper MB. Radiographic pneumonia in young, highly febrile children with leukocytosis before and after universal conjugate pneumococcal vaccination. Pediatr Emerg Care. 2009;25(1):1-7. doi: 10.1097/PEC.0b013e318191dab2.

11. Andreola B, Bressan S, Callegaro S, Liverani A, Plebani M, Da Dalt L. Procalcitonin and C-reactive protein as diagnostic markers of severe bacterial infections in febrile infants and children in the emergency department. Pediatr Infect Dis J. 2007;26(8):672-7. doi: 10.1097/ INF.0b013e31806215e3.

12. Esposito S, Rinaldi VE, Argentiero A, Farinelli E, Cofini M, D’Alonzo R, et al. Approach to neonates and young infants with fever without a source who are at risk for severe bacterial infection. Mediators Inflamm. 2018;2018:4869329. doi: 10.1155/2018/4869329. 